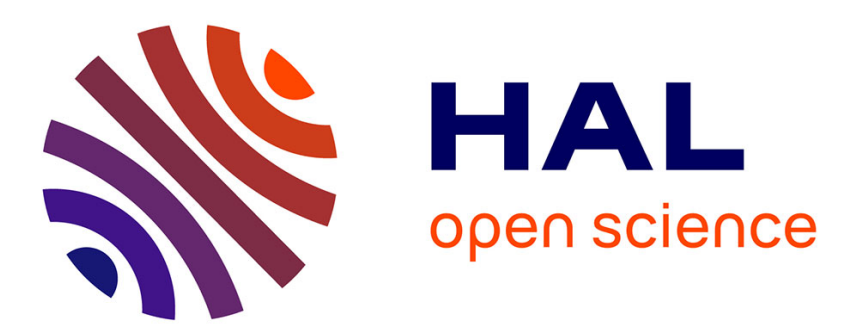

\title{
Experimental validation of a patient-specific model of orthotic action in adolescent idiopathic scoliosis
}

Claudio Vergari, Isabelle Courtois, Eric Ebermeyer, Houssam Bouloussa, Raphaël Vialle, Wafa Skalli

\section{To cite this version:}

Claudio Vergari, Isabelle Courtois, Eric Ebermeyer, Houssam Bouloussa, Raphaël Vialle, et al.. Experimental validation of a patient-specific model of orthotic action in adolescent idiopathic scoliosis. European Spine Journal, 2016, 25 (10), pp.3049-3055. 10.1007/s00586-016-4511-7 . hal-01551697

\author{
HAL Id: hal-01551697 \\ https://hal.science/hal-01551697
}

Submitted on 30 Jun 2017

HAL is a multi-disciplinary open access archive for the deposit and dissemination of scientific research documents, whether they are published or not. The documents may come from teaching and research institutions in France or abroad, or from public or private research centers.
L'archive ouverte pluridisciplinaire HAL, est destinée au dépôt et à la diffusion de documents scientifiques de niveau recherche, publiés ou non, émanant des établissements d'enseignement et de recherche français ou étrangers, des laboratoires publics ou privés. 


\title{
EXPERIMENTAL VALIDATION OF A PATIENT-SPECIFIC MODEL OF ORTHOTIC ACTION IN ADOLESCENT IDIOPATHIC SCOLIOSIS
}

\author{
Claudio Vergari*1, Isabelle Courtois ${ }^{2}$, Eric Ebermeyer ${ }^{2}$, \\ Houssam Bouloussa ${ }^{3}$, Raphaël Vialle ${ }^{3}$ and Wafa Skalli ${ }^{1}$
}

\begin{abstract}
Purpose Personalized modeling of brace action have potential in improving brace efficacy in adolescent idiopathic scoliosis (AIS). Model validation and simulation uncertainty are rarely addressed, limiting the clinical implementation of personalized models. We hypothesized that a thorough validation of a personalized finite element model (FEM) of brace action would highlight potential means of improving the model.
\end{abstract}

Methods 42 AIS patients were included retrospectively and prospectively. Personalized FEMs of pelvis, spine and ribcage were built from stereoradiographies. Brace action was simulated through soft cylindrical pads acting on the ribcage and through displacements applied to key vertebrae. Simulation root mean squared errors (RMSEs) were calculated by comparison with the actual brace action (quantified through clinical indices, vertebral positions and orientations) observed in in-brace stereoradiographies.

Results Simulation RMSEs of Cobb angle and vertebral apical axial rotation was lower than measurement uncertainty in $79 \%$ of the patients. Pooling all patients and clinical indices, $87 \%$ of the indices had lower RMSEs than the measurement uncertainty.

Conclusions In-depth analysis suggests that personalization of spinal functional units mechanical properties could improve the simulation's accuracy, but the model gave good results, thus justifying further research on its clinical application.

Keywords: Finite element model; Spine deformity; Brace; Pediatrics

${ }^{1}$ Arts et Metiers ParisTech, LBM/Institut de Biomecanique Humaine Georges Charpak, 151 bd de l'Hopital, 75013, Paris, France

${ }^{2}$ Unite Rachis, CHU-Hopital Bellevue, 25 Boulevard Pasteur, 42100, Saint-Etienne, France

${ }^{3}$ Department of Paediatric Orthopaedics, Armand Trousseau Hospital, Université Pierre et Marie CurieParis 6, 75571, Paris, France 


\section{Introduction}

Adolescent idiopathic scoliosis (AIS) is a three-dimensional deviation of the spine from its physiological curvature [1]. Progression of the curve is often accompanied by vertebral wedging, ribcage deformity and a loss of spinal sagittal curvature ("flat back") that can induce respiratory or cardiovascular impairment [2] and more in general a decrease in quality of life. Corrective surgery is very invasive, with a loss of spinal motion and a significant risk of complications. Orthotic treatment aims at slowing down curve progression, especially during growth spurt, with a less invasive approach.

While the potential effectiveness of bracing has recently been demonstrated in AIS [3, 4], the planning and fabrication of the brace is still empirical and based on the experience of the clinicians and orthotists. This is partly due to the complex three-dimensional geometry of the scoliotic spine and of its biomechanical behavior; prediction of brace action from qualitative observation is difficult, sometimes resulting in in-brace spinal shapes similar or worse than the out-of-brace spine [5].

The potential of biomechanical finite element models (FEMs) as a tool in orthopedics has been proven in several applications, such as surgical planning, implant design, etc. Several FEMs of the trunk have been reported in the literature $[6,7]$. Recent improvement in spinal imaging and feature detection $[8,9]$ allowed the development of subject-specific trunk models, while at the same time work has been done to introduce FEMs in brace design [10-12]. These models, however, retain a qualitative character because their experimental validation is often lacking or incomplete [13].

Our group recently presented a geometrical and clinically relevant framework for the evaluation of FEM for brace action [13]. The hypothesis of the present work was that a thorough validation of a personalized FEM of brace action would highlight potential means of improvement by quantifying of the model's reliability and weaknesses.

\section{Methods}

\section{Subjects}

Forty-two patients diagnosed with progressive AIS were included both retrospectively and prospectively in this multicentric study: 38 girls and 4 boys between 7 and 17 years old, $26.2^{\circ}$ $\pm 14.4^{\circ} \mathrm{Cobb}$ angle. All were prescribed a treatment by either cast or brace; progressive AIS was diagnosed by the prescribing clinician. Stereoradiographs were acquired (EOS system, EOS imaging, Paris, France) with the patient in free standing position [14] at treatment decision (out of brace, $T_{0}$ ) and in-brace $\left(\mathrm{T}_{1}\right.$, Fig. 1). $\mathrm{T}_{1}$ acquisition was performed between 0 (i.e. same day) and 7 months after $\mathrm{T}_{0}$. The study was approved by the ethical committee (CPP 6001 Ile de France V).

\section{Subject specific model}

3D reconstruction of the pelvis [15], spine [9] and ribcage [8] was performed by an experienced user using validated methods. The pelvis was reconstructed in the $\mathrm{T}_{0}$ geometry and rigidly translated in the $T_{1}$ geometry in order to define the same robust subject frame of reference in both configuration. The geometry of each vertebra (Fig. 2) was calculated by averaging the $\mathrm{T}_{0}$ and $\mathrm{T}_{1}$ vertebral geometries. 

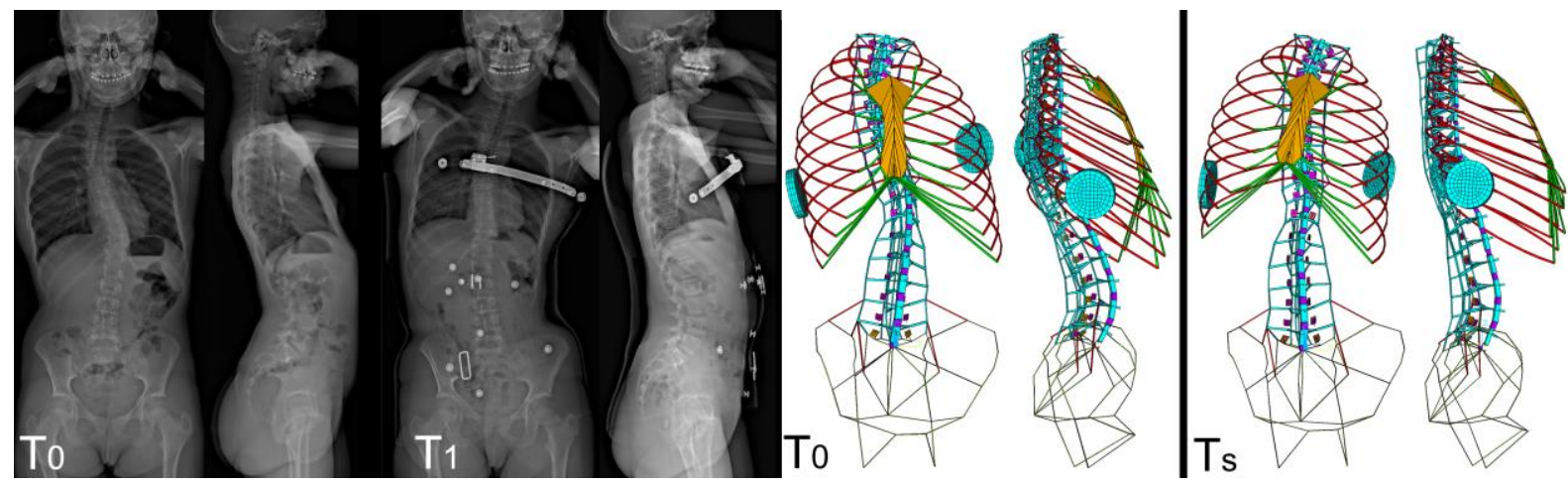

Fig. 1 Example of stereo-radiographies at decision of treatment $\left(\mathrm{T}_{0}\right)$ and in-brace $\left(\mathrm{T}_{1}\right)$; personalized finite element model buildt from $3 \mathrm{D}$ reconstruction at decision of treatment $\left(\mathrm{T}_{0}\right)$ and after simulation of brace action ( $\mathrm{T}_{\mathrm{S}}$ ). The cylindrical structure on the rib cage are the brace's thoracic pads; intercostal membrane was hidden for clarity.

A personalized finite element beam model (Fig. 1) was then generated as previously described $[13,16]$, including the pelvis, sacrum, thoracic and lumbar vertebrae (Fig 2), posterior articulations, intervertebral discs, ligaments, and rib cage. Ribs mechanical properties were personalized according to the patient's Risser sign [17] while their cross-sectional areas were adapted to the vertebral level, according to an existing database of scoliotic adolescent rib morphology [18]. The model was implemented in ANSYS V11 (Ansys Inc., Canonsburg, PA).

\section{Boundary conditions}

Boundary conditions were implemented by displacing only those regions where the brace was acting, while letting the rest of the trunk respond to this mechanical loading.

These anatomical regions were identified by observing the deformation of soft tissues and the radiopaque components of the brace [13]. Those pads pushing on the lumbar region or posteriorly on the spine where implemented by displacing the corresponding vertebra. Those pads acting on the rib cage were explicitly implemented as soft cylinders (Fig. 1; 485 nodes, 433 hexahedral elements, $0.01 \mathrm{MPa}$ Young's modulus) pushing on the ribs through mechanical contact. Pelvis and $\mathrm{T} 1$ vertebra were displaced in the $\mathrm{T}_{1}$ geometry to reproduce patient's balance and posture. Displacements were measured as differences between the $3 \mathrm{D}$ reconstructions at $\mathrm{T}_{0}$ and $\mathrm{T}_{1}$ in the same pelvis-based frame.

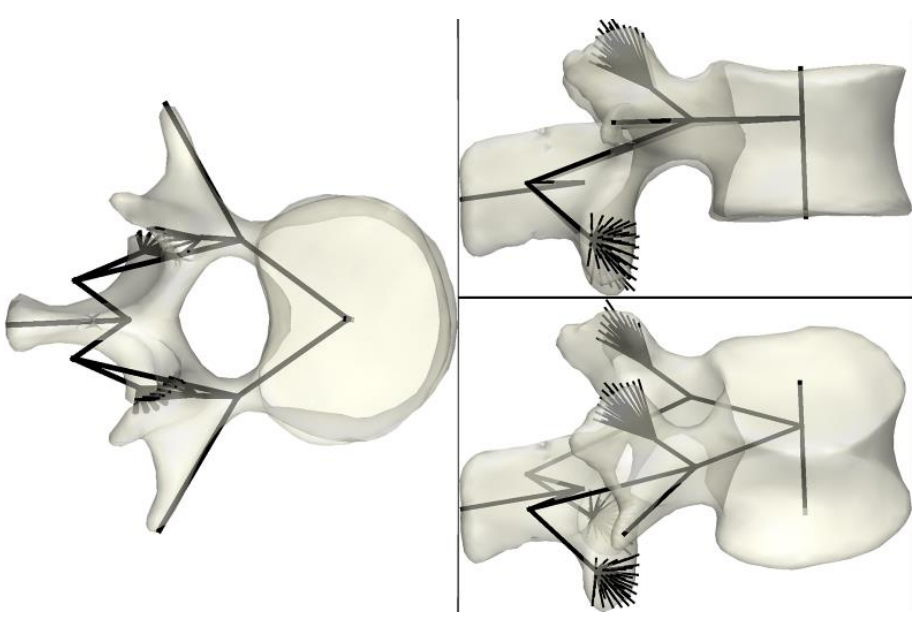

Fig. 2 Top, lateral and oblique view of a 3D model of a L1 vertebra: 3D volume reconstruction from stereoradiography and beam model of the vertebra. The vertebral body is composed of a single beam with two beams linking it to the posterior arch, spinous process and vertebral articulations. The latter, are modelled with shell elements (not represented for clarity) held in place by an array of structural beams. The endings of the lateral and spinous processes provide insertion points for ligaments. 


\section{Analysis and statistics}

The 3D model yielded by the simulated inbrace geometry of the patient's trunk $\left(\mathrm{T}_{\mathrm{S}}\right)$ was used to calculate vertebral positions, their orientations and the following relevant clinical indices (Table 1): kyphosis, lordosis, Cobb angle, vertebral axial rotation at the apical level (VAR), torsion index and 3D rib hump. Root mean squared errors (RMSE) and maximal differences were calculated between these parameters in the $T_{1}$ geometry and the simulated ones $\left(\mathrm{T}_{\mathrm{S}}\right)$. These values were then compared with a measurement uncertainty corresponding to the error ( $\varepsilon$, Table 1) expected when comparing two 3D reconstructions $\left(\mathrm{T}_{0}\right.$ and $\left.\mathrm{T}_{1}\right)$ with known uncertainties, i.e. $\epsilon=\sqrt{2\left(2 R M S_{S D}\right)^{2}}$, where $2 \mathrm{RMS}_{\mathrm{SD}}$ is the previously determined reproducibility of the $3 \mathrm{D}$ reconstruction $[8$, 9].

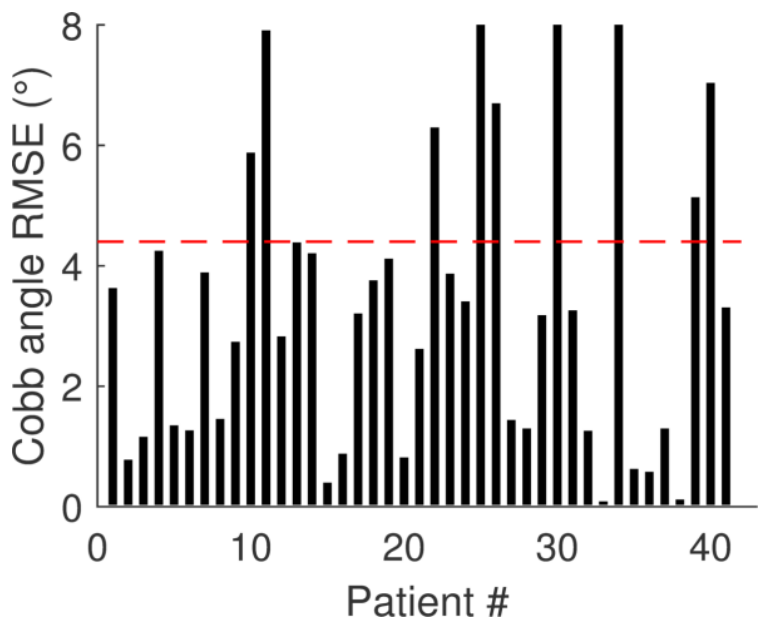

Fig. 3 Root mean square error (RMSE) of Cobb angle between in-brace and simulated geometries for all patients: the dashed line represents the measurement uncertainty.

A "patient RMSE" was determined for each patient by calculating the RMS of the differences between all simulated and actual parameters, as well as an overall "brace action" which was

\section{Table 1.}

Measurement uncertainty, root mean square error (RMSE) between in-brace $\left(\mathrm{T}_{1}\right)$ and simulated geometries $\left(\mathrm{T}_{\mathrm{S}}\right)$, and number of values out of 42 patients lower than the measurement uncertainty. (VAR: vertebral axial rotation at the apex).

\begin{tabular}{|c|c|c|c|c|}
\hline & $\begin{array}{c}\text { Measurement } \\
\text { uncertainty }\end{array}$ & $\begin{array}{c}\text { Maximal } \\
\text { difference } \\
\mathrm{T}_{\mathrm{s}}-\mathrm{T}_{1} \\
\end{array}$ & $\begin{array}{l}\text { RMSE between } T_{s} \\
\text { and } T_{1}\end{array}$ & $\begin{array}{c}\# \text { values }< \\
\text { uncertainty }\end{array}$ \\
\hline \multicolumn{5}{|l|}{ Clinical indices } \\
\hline T1/T12 Kyphosis $\left({ }^{\circ}\right)$ & 7.8 & 6.7 & 2.5 & $100 \%$ \\
\hline T4/T12 Kyphosis $\left({ }^{\circ}\right)$ & 5.4 & 8.4 & 3.8 & $83 \%$ \\
\hline L1/L5 Lordosis ( $\left.{ }^{\circ}\right)$ & 6.5 & 9.0 & 4.0 & $93 \%$ \\
\hline Cobb angle $\left({ }^{\circ}\right)$ & 4.4 & 87 & 4.1 & $79 \%$ \\
\hline $\operatorname{VAR}\left({ }^{\circ}\right)$ & 4.8 & 9.3 & 3.9 & $79 \%$ \\
\hline Torsion $\left({ }^{\circ}\right)$ & 5.7 & 12.7 & 4.7 & $86 \%$ \\
\hline 3D Rib Hump $\left({ }^{\circ}\right)$ & 7.1 & 12.9 & 4.4 & $90 \%$ \\
\hline \multicolumn{5}{|l|}{ Vertebral orientation } \\
\hline Frontal rotation $\left({ }^{\circ}\right)$ & 3.4 & 4.8 & 2.6 & $90 \%$ \\
\hline Lateral rotation $\left({ }^{\circ}\right)$ & 3.3 & 4.5 & 2.7 & $81 \%$ \\
\hline Axial rotation $\left({ }^{\circ}\right)$ & 5.5 & 14.1 & 5.0 & $86 \%$ \\
\hline \multicolumn{5}{|l|}{ Vertebral position } \\
\hline Postero-anterior (mm) & 1.7 & 5.9 & 2.3 & $50 \%$ \\
\hline Lateral $(\mathrm{mm})$ & 1.6 & 4.4 & 2.1 & $45 \%$ \\
\hline Vertical (mm) & 1.1 & 2.3 & 0.9 & $81 \%$ \\
\hline
\end{tabular}


determined as the RMS of the difference between the clinical indices in $T_{0}$ and $T_{1}$ reconstruction.

Pearson correlation coefficients was used to analyse correlations; significance was set at $\mathrm{p}<$ 0.05. Calculations were performed with Matlab 2014b (Mathworks, Natick, MA).

\section{Results}

Bracing had an overall positive effect on the patients' clinical indices in the coronal plane (Table 2), but it had little or negative effect in the transversal and sagittal planes. Cobb angle was decreased in $70 \%$ of the patients (average correction: $10.4^{\circ}$ ), but it increased more than the measurement uncertainty in 2 patients $\left(5.4^{\circ}\right.$ and $\left.6.8^{\circ}\right)$. Torsion and VAR decreased in 24 and $25 \%$ of the patients, respectively, but it also increased in 10 and $14 \%$, respectively. Kyphosis and lordosis decreased in approximately half of the patients (Table 2).

A typical simulation lasted about 10 minutes on a desktop PC and presented no convergence issues. Overall simulation performance is reported in Table 1; kyphosis, lordosis and Cobb angles RMSEs were lower than the measurement uncertainty. Fig. 3 and Fig. 4 show the RMSE of Cobb angle and vertebral axial rotation at apical level for each patient. Full clinical data at $\mathrm{T}_{0}, \mathrm{~T}_{1}$ and $\mathrm{T}_{\mathrm{s}}$ are reported as supplementary material (Online

Resource 1). Pooling all patients and clinical indices, $87 \%$ of the indices had lower errors than the corresponding measurement uncertainty.

Errors on vertebral orientations were lower than the measurement uncertainty (Table 1). Average RMSEs in vertebral positions were higher than the measurement uncertainty in the postero-anterior and lateral directions, but slightly lower in the vertical direction. Overall RMSE in vertebral position was $1.9 \mathrm{~mm}$; when pooled together, more than $59 \%$ of the 714 considered vertebrae (42 patients times 17 vertebrae) showed lower position errors than the measurement uncertainty.

No correlation was observed between the patient's simulation error and the patient's brace action $(\mathrm{p}>0.05)$ nor the clinical parameters at $\mathrm{T}_{0}(\mathrm{p}>0.05)$. Table 3 reports measured and simulated brace action on the clinical indices for the 3 patients with the lowest simulation errors (patient RMSE $\leq 1.5^{\circ}$ ) and 4 patients with the highest ones (patient $\mathrm{RMSE} \geq 4.4^{\circ}$ ).

\section{Table 2}

Effect of bracing on the patients' clinical parameters reported as number (and percentage) of patients which had each value significantly decreased (compared to measurement uncertainty), unchanged or significantly increased. Average correction is also reported.

\begin{tabular}{lcccc}
\hline \multicolumn{1}{c}{ Clinical indices } & Value increased & $\begin{array}{c}\text { Value } \\
\text { unchanged }\end{array}$ & $\begin{array}{c}\text { Value } \\
\text { decreased }\end{array}$ & $\begin{array}{c}\text { Average } \\
\text { correction }\left(^{\circ}\right)\end{array}$ \\
\hline T1/T12 Kyphosis & $4(10 \%)$ & $18(43 \%)$ & $20(48 \%)$ & $-4,8$ \\
T4/T12 Kyphosis & $5(12 \%)$ & $14(33 \%)$ & $23(55 \%)$ & $-4,2$ \\
L1/L5 Lordosis & $2(5 \%)$ & $15(36 \%)$ & $25(60 \%)$ & $-5,9$ \\
Cobb angle & $2(5 \%)$ & $9(21 \%)$ & $31(74 \%)$ & $-10,4$ \\
VAR & $6(14 \%)$ & $25(60 \%)$ & $11(26 \%)$ & $-1,7$ \\
Torsion & $4(10 \%)$ & $28(67 \%)$ & $10(24 \%)$ & $-1,3$ \\
3D Rib Hump & $1(2 \%)$ & $28(67 \%)$ & $13(31 \%)$ & $-2,7$ \\
\hline
\end{tabular}




\section{Table 3}

Absolute differences between out-of-brace $\left(\mathrm{T}_{0}\right)$ and in-brace $\left(\mathrm{T}_{1}\right)$ clinical indices (i.e., brace action) and absolute differences between simulated $\left(\mathrm{T}_{\mathrm{s}}\right)$ and out-of-brace clinical indices (i.e., simulated brace action) for the three patients presenting the lowest simulation errors (\#16, \#32 and \#38) and four patients with the highest ones.

\begin{tabular}{|c|c|c|c|c|c|c|c|c|c|c|c|c|c|c|}
\hline & \multicolumn{2}{|c|}{ Patient \#16 } & \multicolumn{2}{|c|}{ Patient \#32 } & \multicolumn{2}{|c|}{ Patient \#38 } & \multicolumn{2}{|c|}{ Patient \#11 } & \multicolumn{2}{|c|}{ Patient \#28 } & \multicolumn{2}{|c|}{ Patient \#36 } & \multicolumn{2}{|c|}{ Patient \#40 } \\
\hline T1/T12 Kyphosis $\left({ }^{\circ}\right)$ & 2.0 & 1.4 & 12.2 & 1.5 & 2.8 & 0.2 & 0.9 & 6.7 & 17.8 & 2.0 & 8.3 & 3.2 & 0.3 & 0.1 \\
\hline L1/L5 Lordosis $\left({ }^{\circ}\right)$ & 5.5 & 0.3 & 13.6 & 0.4 & 8.8 & 0.4 & 3.2 & 4.6 & 13.5 & 5.7 & 9.9 & 6.9 & 5.5 & 1.4 \\
\hline Cobb angle $\left(^{\circ}\right)$ & 0.3 & 0.9 & 22.4 & 1.3 & 13.5 & 0.1 & 2.7 & 7.9 & 19.8 & 1.3 & 7.0 & 0.6 & 20.2 & 7.1 \\
\hline $\operatorname{VAR}\left({ }^{\circ}\right)$ & 2.0 & 0.2 & 7.9 & 0.8 & 1.9 & 0.1 & 1.4 & 0.8 & 19.7 & 9.3 & 5.7 & 8.5 & 1.9 & 5.1 \\
\hline 3D Rib Hump $\left(^{\circ}\right)$ & 2.3 & 1.0 & 4.3 & 2.9 & 0.9 & 2.0 & 7.9 & 2.4 & 1.8 & 2.4 & 7.0 & 1.2 & 5.5 & 2.6 \\
\hline
\end{tabular}




\section{Discussion}

Biomechanical FEMs have the potential of introducing objectiveness and robustness in the design of braces for scoliotic correction. The difficulties of experimental validation of these models, mainly due to protocol design and clinical data collection, are slowing down the establishment of an effective framework to simulate and predict brace action on a given scoliotic subject's trunk. However such validation is essential to translate a model "from bench to bedside".

In this work we presented the validation of an improvement on previously described FEM $[13,16]$, which was preliminarily validated on a small cohort of 10 patients. In this instance, the boundary conditions were improved by including an explicit model of those brace pads acting on the ribcage. Work is under way

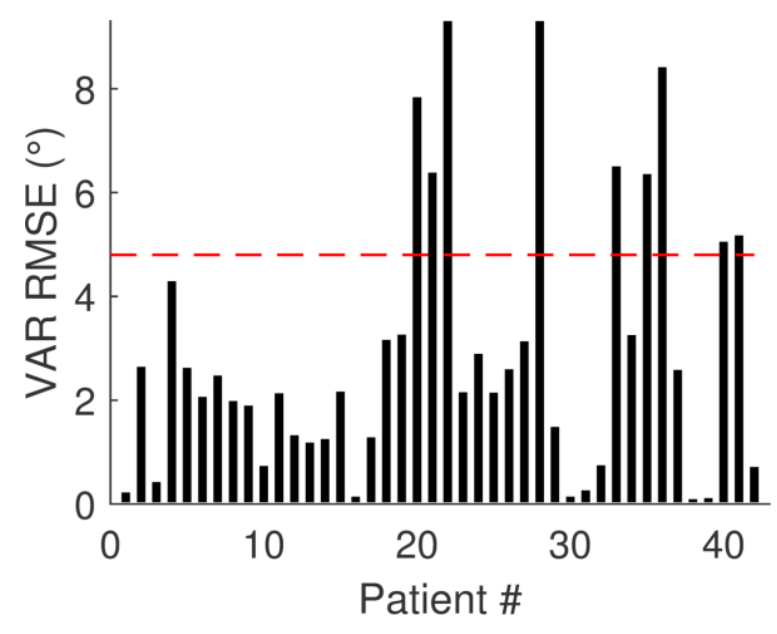

Fig. 4 Root mean square error (RMSE) of vertebral axial rotation at apical level (VAR) between in-brace and simulated geometries for all patients: the dashed line represents the measurement uncertainty. to include skin and muscle layers in the model, which will allow investigating their complex interaction with the pads. Further improvements should include gravity, muscular action and neuromuscular control.

To our knowledge, this is the first series on 42 patients both for extensive quantitative evaluation of the $3 \mathrm{D}$ brace effect and for model evaluation. Bracing had a positive effect on the patient's clinical indices in the frontal plane where Cobb angle improved in $74 \%$ of the cohort (Table 2, Online Resource 1). This is slightly better than the 50\% cohort improvement previously reported by Courvoisier et al. [5]. The absolute Cobb angle correction observed in this study was similar to the one previously reported by Lebel et al. [19] $\left(-10.4^{\circ}\right.$ against $\left.\sim 14^{\circ}\right)$, but VAR correction was lower $\left(-1.7^{\circ}\right.$ against $\left.-6.5^{\circ}\right)$. Comparison with previous studies, in particular concerning absolute values of correction, is difficult because of differences in the initial cohort (age, curve topology), brace compliance [3], etc. Moreover, brace planning relies on the experience of the orthotist and of the clinician, which adds to the variability of the results on brace effect.

Lordosis and kyphosis decreased in about $50 \%$ of the cohort (Table 2). Hypolordosis and hypokyphosis are known features of the scoliotic spine [20], and it is well reported that brace treatment tend to flatten the sagittal alignment [5]. The horizontal plane (torsion and VAR) was unchanged or worsened in the majority of patients, consistently with previous studies [5]. It has been shown that restoration of sagittal spinal alignment and horizontal plane improves the rate of success scoliosis surgery [21] and global patient posture, but these results suggest that current brace designs tend to have little impact on the three-dimensional character of the scoliotic spine. Personalized and robust modeling of the trunk could drastically improve brace design and effectiveness.

One limitation of this work is that several types of braces and scoliosis severities were pooled together. Analyzing the effectiveness of a specific type of bracing, however, was beyond the scope of this work. The heterogeneity of bracing and scoliosis types actually allowed the model to be tested in several different situations. The second limitation is that the in-brace radiography 
was needed to define the boundary conditions. However, collecting the in-brace radiography and comparing it to the simulation results represents a powerful means of validating the model.

Comparison with the previous model [13] shows improvements of the simulation performance in vertebral positions and orientations, as well as in all clinical indices but T4/T12 Kyphosis, which remained almost unchanged $\left(3.8^{\circ}\right.$ against $3.5^{\circ}$ in the previous work, Table 1$)$. It is possible that this parameter is more influenced by the vertebral thoracic pads than by the newly introduced ribcage pads, or that a limit has been reached for this parameter; a further improvement might require reducing the uncertainty of the 3D reconstruction.

Statistical analysis showed that simulation accuracy did not depend on the degree of correction induced by the brace nor on the degree of spine deformity. In other words, the model had the same reliability for different curves and brace-induced displacements.

For $80 \%$ of the patients, RMSEs were within the limits of uncertainty. For the remaining $20 \%$ of the patients, the case-by-case analysis shows potential ways of improving the model. For instance, patient \#40 (Table 3) shows large differences in Cobb angle and vertebral axial rotation at the apex (VAR). In-depth analysis showed that the brace increased his VAR by $2^{\circ}$. In the simulation, VAR increased, but it actually increased too much $\left(7^{\circ}\right)$. At the same time, torsion decreased in the simulation, as well as in the measured stereoradiography, but not enough $\left(2^{\circ}\right)$. This suggests that the scoliotic curve in the simulation rotated too much in the axial plane, and it rotated too much rigidly (hence, the small change in torsion). A different distribution of spinal function units stiffness along the spine, and in particular at the junctional levels, might have decreased the VAR variation in the simulation while allowing a more natural detorsion of the curve.

In patient \#28 (Table 3), VAR decreased by $18^{\circ}$, while in the simulation VAR decreased by $20^{\circ}$. Torsion decreased by $13^{\circ}$ while it only decreased by $1^{\circ}$ in the simulation. Once again, this patient's spine seems too stiff in rotation; a decrease in his functional units mechanical properties (discs, vertebrae, articular contacts) might improve the simulation. Cobb angle, however, present a small difference of $1.3^{\circ}$. This case underlines the importance of not basing the validation on the frontal plane only; such approach would have missed the simulation's actual performance on the horizontal plane.

Mechanical properties of the ribs were personalized with subject age, while their geometry was accurate because of recent developments in 3D reconstruction [8]. This have probably played a role in the model performance, given how the ribs transmits loads to the spine. Although the intervertebral disc mechanical properties were not personalized, the simulations gave satisfactory results for the majority of the patients, thus highlighting the importance of the geometry in the behavior of this complex structure. However, it is likely that more severe curves (pre-surgery) would present stiffer spines, thus needing a specific personalization of the functional units' mechanical properties. Methods for obtaining disc properties in-vivo are being investigated [22-24], which will allow introducing personalized disc properties.

As hypothesized, a through validation of the model on a relatively large number of subjects allowed highlighting the model's limitations and potential means of improvement. Future work will aim at determining which mechanical properties are key to lower simulation errors, but also at developing non-invasive techniques to personalize mechanical properties thus improving the model towards the prediction of brace action. However, as of this day, it will be possible to modify the boundary conditions of the model to explore alternative and more effective brace action. 


\section{Acknowledgements}

The authors are grateful to the ParisTech BiomecAM chair program on subject-specific musculoskeletal modelling (with the support of ParisTech and Yves Cotrel Foundations, Société Générale, Proteor and Covea) and to the "Investissements d'Avenir" program for funding the CORSIN Project, in collaboration between Proteor and our institution. We would also like to thank Ms Sonia Simoes for her technical help.

\section{Conflict of interest statement}

No conflict of interest to disclose. 


\section{References}

1. Dubousset J (1994) Three-dimensional Analysis of the Scoliotic Deformity. In: The Pediatric Spine: Principles and Practice. Raven Press L.

2. Asher M, Burton D (2006) Adolescent idiopathic scoliosis: natural history and long term treatment effects. Scoliosis 1:2

3. Weinstein SL, Dolan LA, Wright JG, Dobbs MB (2013) Effects of Bracing in Adolescents with Idiopathic Scoliosis. New Engl J Med 369:1512-1521. doi: doi:10.1056/NEJMoa1307337

4. Lou EM, Hill D, Raso J, Moreau M, Hedden D (2015) How quantity and quality of brace wear affect the brace treatment outcomes for AIS. Eur Spine J:1-5. doi: 10.1007/so0586-0154233-2

5. Courvoisier A, Drevelle X, Vialle R, Dubousset J, Skalli W (2013) 3D analysis of brace treatment in idiopathic scoliosis. Eur Spine J:1-7. doi: 10.1007/soo586-013-2881-7

6. Jalalian A, Gibson I, Tay EH (2013) Computational Biomechanical Modeling of Scoliotic Spine: Challenges and Opportunities. Spine Deformity 1:401-411. doi: http://dx.doi.org/10.1016/j.jspd.2013.07.009

7. Wang W, Baran GR, Betz RR, Samdani AF, Pahys JM, Cahill PJ (2014) The Use of Finite Element Models to Assist Understanding and Treatment For Scoliosis: A Review Paper. Spine Deformity 2:10-27. doi: http://dx.doi.org/10.1016/j.jspd.2013.09.007

8. Aubert B, Vergari C, Ilharreborde B, Courvoisier A, Skalli W (In Press) 3 D Reconstruction of rib cage geometry from biplanar radiographs using a statistical parametric model approach. Comput Methods Biomech Biomed Eng Imaging Vis. doi: http://dx.doi.org/10.1080/21681163.2014.913990

9. Humbert L, De Guise JA, Aubert B, Godbout B, Skalli W (2009) 3D reconstruction of the spine from biplanar X-rays using parametric models based on transversal and longitudinal inferences. Med Eng Phys 31:681-687. doi: 10.1016/j.medengphy.2009.01.003

10. Cobetto N, Aubin C-E, Clin J, Le May S, Desbiens-Blais F, Labelle H, Parent S (2014) Braces Optimized With Computer-Assisted Design and Simulations Are Lighter, More Comfortable, and More Efficient Than Plaster-Cast Braces for the Treatment of Adolescent Idiopathic Scoliosis. Spine Deformity 2:276-284. doi: http://dx.doi.org/10.1016/j.jspd.2014.03.005

11. Gignac D, Aubin CÉ, Dansereau J, Labelle H (200o) Optimization method for 3D bracing correction of scoliosis using a finite element model. Eur Spine J 9:185-19o. doi: 10.1007/s005860000135

12. Desbiens-Blais F, Clin J, Parent S, Labelle H, Aubin C-E (2012) New brace design combining $\mathrm{CAD} / \mathrm{CAM}$ and biomechanical simulation for the treatment of adolescent idiopathic scoliosis. Clin Biomech 27:999-1005. doi: 10.1016/j.clinbiomech.2012.08.006

13. Vergari C, Ribes G, Aubert B, Adam C, Miladi L, Ilharreborde B, Abelin-Genevois K, Rouch P, Skalli W (2015) Evaluation of a patient-specific finite element model to simulate conservative treatment in adolescent idiopathic scoliosis. Spine Deformity 3:4-11. doi: http://dx.doi.org/10.1016/j.jspd.2014.06.014

14. Steffen J-S, Obeid I, Aurouer N, Hauger O, Vital J-M, Dubousset J, Skalli W (2010) 3D postural balance with regard to gravity line: an evaluation in the transversal plane on 93 patients and 23 asymptomatic volunteers. Eur Spine J 19:760-767. doi: 10.1007/soo586-009-1249-5

15. Mitton D, Deschênes S, Laporte S, Godbout B, Bertrand S, de Guise JA, Skalli W (2006) 3D reconstruction of the pelvis from bi-planar radiography. Comput Methods Biomech Biomed Eng 9:1-5. doi: 10.1080/10255840500521786

16. Descrimes JL, Aubin CE, Skalli W, Zeller R, Danserau J, Lavaste F (1995) Introduction des facettes articulaires dans une modélisation par éléments finis de la colonne vertébrale et du thorax scoliotique : aspects mécaniques. Rachis 7:301-314 
17. Pezowicz C, Glowacki M (2012) The mechanical properties of human ribs in young adult. Acta of bioengineering and biomechanics 14:53-60

18. Sandoz B, Badina A, Laporte S, Lambot K, Mitton D, Skalli W (2013) Quantitative geometric analysis of rib, costal cartilage and sternum from childhood to teenagehood. Med Biol Eng Comput 51:971-979. doi: 10.1007/s11517-013-1070-5

19. Lebel D, Al-Aubaidi Z, Shin E-J, Howard A, Zeller R (2013) Three dimensional analysis of brace biomechanical efficacy for patients with AIS. Eur Spine J 22:2445-2448. doi: 10.1007/s00586-013-2921-3

20. Malfair D, Flemming AK, Dvorak MF, Munk PL, Vertinsky AT, Heran MK, Graeb DA (2010) Radiographic Evaluation of Scoliosis: Review. American Journal of Roentgenology 194:S8-S22. doi: 10.2214/AJR.07.7145

21. Schwab FJ, Lafage V, Farcy J-P, Bridwell KH, Glassman S, Shainline MR (2008) Predicting Outcome and Complications in the Surgical Treatment of Adult Scoliosis. Spine 33:22432247. doi: 10.1097/BRS.obo13e31817did4e

22. Vergari C, Dubois G, Vialle R, Gennisson JL, Tanter M, Dubousset J, Rouch P, Skalli W (In Press) Lumbar annulus fibrosus biomechanical characterization in healthy children by ultrasound shear wave elastography. Eur Radiol. doi: 10.1007/so0330-015-3911-o

23. Lafon Y, Lafage V, Steib JP, Dubousset J, Skalli W (2010) In vivo distribution of spinal intervertebral stiffness based on clinical flexibility tests. Spine 35:186-193. doi: 10.1097/BRS.obo13e3181b664b1

24. Little JP, Adam CJ (2009) The effect of soft tissue properties on spinal flexibility in scoliosis: biomechanical simulation of fulcrum bending. Spine 34:E76-82. doi: 10.1097/BRS.obo13e31818ad584 